\title{
Vertex, Revista Argentina de Psiquiatría a través de su editor y sus editoriales: los años de formación y el exilio
}

\author{
Daniel Matusevich $\oplus$, Dalia Szulikø y Aldo Calzolariø
}

\begin{abstract}
RESUMEN
Vertex, Revista Argentina de Psiquiatría es una de las pocas publicaciones de la especialidad editadas en español que está incluida en PubMed. Durante los 30 años de existencia (1990 hasta el presente) ha sido dirigida por el Dr. Juan Carlos Stagnaro, quien es el autor exclusivo de los editoriales. Mediante el análisis de sus palabras clave y de extensas entrevistas semiestructuradas, este trabajo indaga sobre aspectos biográficos del joven Stagnaro para comprender la génesis de la revista, su impronta científico-política y las líneas editoriales que abordó. Se trabajó sobre los años de formación en la Argentina, el exilio en Francia durante la última dictadura militar y aspectos formativos en psiquiatría que le permitieron, al regreso a la Argentina, fundar la revista.
\end{abstract}

Palabras clave: psiquiatría, salud mental, biografía, Juan Carlos Stagnaro.

\section{VERTEX JOURNAL THROUGH ITS EDITOR AND ITS EDITORIALS: THE FORMATIVE YEARS AND THE EXIL ABSTRACT}

Vertex, Revista Argentina de Psiquiatria is one of the few journal of this specialty published in Spanish that is included in PubMed. During its 30 years of existence (1990 to present) it has been directed by Dr. Juan Carlos Stagnaro, who is the exclusive author of the editorials. Through the analysis of their keywords and extensive semi-structured interviews, this work investigates the biographical aspects of the young Stagnaro in order to understand the genesis of the journal, its scientific-political imprint and the editorial linesit addressed. The work describes the formative years in Argentina, the exile in France during the last military dictatorship and formative aspects in psychiatry that allowed him, upon his return to Argentina, to create the journal.

Key words: psychiatry, mental health, biography, Juan Carlos Stagnaro.

Rev. Hosp. Ital. B.Aires 2021; 41(3): 140-146.

\section{INTRODUCCIÓN}

Vertex Revista Argentina de Psiquiatría (ISSN 0327$6139)^{1}$ se publica de manera bimestral, indizada en los acopios bibliográficos SCIMAGO, SCIELO, LILACS y MEDLINE, PubMed, fue fundada en 1990 por Juan Carlos Stagnaro (Fig. 1, desde ahora JCS), Dominique Wintrebert y Daniel Spiguel. Inicialmente fue una dirección compartida, pero poco después Spiguel se retiró de la publicación y Wintrebert quedó como Director para Europa. JCS la ha dirigido unipersonalmente desde entonces. Él mismo viene realizando en los últimos treinta años una intensa tarea académica y política en la psiquiatría argentina, de la cual la revista es un componente fundamental. El hecho de ser una de las tres únicas publicaciones de psiquiatría en español que aparece en $\mathrm{PubMed}^{2}$ permite suponer que tiene un impacto significativo en la comunidad de profesionales de Salud Mental hispanohablante.

Este trabajo es parte de la tesis doctoral que uno de nosotros (DM) está realizando en el Instituto Universitario del Hospital Italiano de Buenos Aires; una de las premisas de dicha tesis plantea que la historia de JCS y la historia de Vertex han estado y están fuertemente relacionadas. Esto se refleja no solo en los artículos publicados sino también en la naturaleza de las líneas editoriales y en su evolución a lo largo del tiempo. Trabajar en el análisis de la historia reciente implica reconocer el impacto que esta tiene en un pasado "actual" o, más bien, en un pasado en permanente proceso de "actualización" y que, por tanto, interviene en las proyecciones futuras.

Franco y Lvovich ${ }^{3}$ plantean que;

“...en las últimas décadas se ha constatado en distintas latitudes el crecimiento de lo que ha dado en llamarse, según las diversas denominaciones nacionales, Historia del tiempo presente, Historia inmediata o Historia reciente. Esta última es la más frecuente en la Argentina y en varios países de América Latina, aportando una designación que define y recorta trayectorias profesionales, campos de estudio y pertenencias institucionales. 


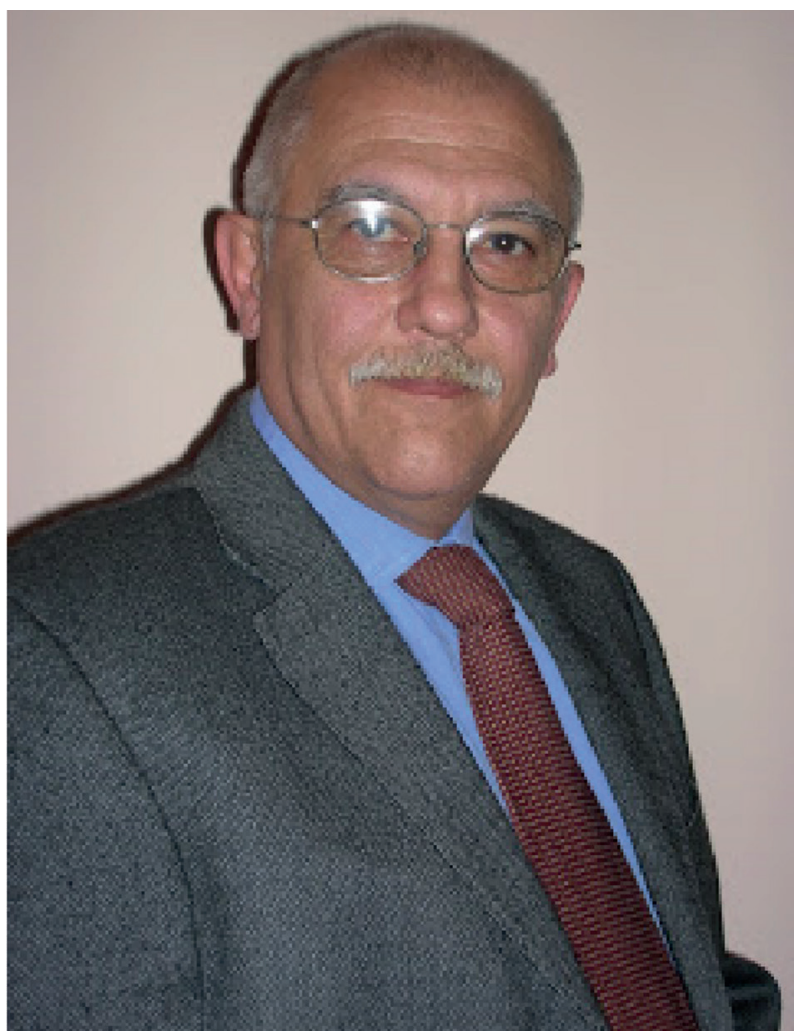

Figura 1. Juan Carlos Stagnaro, 2021.

El concepto de historia reciente refiere, por supuesto, al estudio de pasados próximos, aunque esta obvia constatación no agota su definición. En diversos momentos se postuló que la cercanía en el tiempo resultaba un límite para la operación historiográfica, sea por la postulación de la necesidad de cierta distancia temporal como un requisito ineludible o por la constatación de la dificultad para acceder a los archivos necesarios para su estudio. Sin embargo, en la medida en que los historiadores han empleado diversas fuentes, incluidas con frecuencia las orales, y que se ha ampliado el universo de documentos disponibles, este último señalamiento ha perdido peso". Por eso en este trabajo hemos decidido combinar entrevistas con análisis de documentos, en este caso editoriales, para así poner en relación pasado y presente en forma interactiva como estrategia para ampliar los sentidos de la investigación. También caímos en la tentación que plantea Levín cuando sostiene que:

"...la gran expansión de la historia reciente no podría entenderse sin la enorme atracción que ese pasado ejerce sobre las nuevas generaciones de historiadores que lo interpelan a partir de preguntas propias de su propia época"4.

Solnit sostiene que la verdad no reside exclusivamente en los acontecimientos y en los escritos, sino también en los deseos, las esperanzas y las necesidades de los protagonistas de los acontecimientos ${ }^{5}$. Aplicado esto a nuestro estudio, podría afirmarse que los editoriales de Vertex no son notas aisladas que ilustran diferentes momentos del quehacer de la psiquiatría y la Salud Mental en la Argentina sino una continuidad de casi doscientas páginas, escritas por la misma persona, en las cuales fueron apareciendo textos dedicados a la clínica psiquiátrica enlazados con notas históricas, epistemológicas y políticas.

De esta forma se fue delineando un corpus específico que dio cuenta de un modo de pensar la psiquiatría a lo largo de los últimos treinta años de evolución de la especialidad en la Argentina y en el mundo; este corpus no debe ser imaginado como un territorio bien delimitado sino más bien como una serie de senderos y ríos sinuosos que atraviesan múltiples regiones: su historia está formada más por cruces, ramificaciones y enredos que por caminos rectos. El editorial es un género periodístico con rasgos claramente definidos y que goza de bastante tradición; sin embargo, apenas existen estudios monográficos sobre los editoriales científicos, y las escasas investigaciones encontradas en las búsquedas realizadas han centrado su interés en el carácter argumentativo y persuasivo del género, mientras que los rasgos estructurales, estilísticos y formales han quedado relegados a un segundo plano ${ }^{6,7}$. Las referencias que conciernen a este último aspecto aparecen en la bibliografía de manera dispersa y sobre él no existe unanimidad de enfoques; las referencias consultadas nos ofrecen pistas lo suficientemente válidas como para perfilar el origen de este género en la Inglaterra de comienzos del siglo XVIII ${ }^{7}$. Por otra parte, no hemos encontrado ningún trabajo dedicado a estudiar o analizar editoriales de revistas de psiquiatría. El mismo Alcíbar Cuello argumenta, refiriéndose a los editoriales de los diarios, que son un género de opinión por medio del cual el periódico como institución social enjuicia aquellos acontecimientos de la actualidad que considera relevantes desde un punto de vista social, político, económico o cultural ${ }^{6}$. Del mismo modo, a través de ellos, la revista juzga, según su propia perspectiva ideológica, los hechos de trascendencia en un área. Su análisis adquiere interés al intentar dilucidar los principales puntos de vista en torno a las discusiones de la disciplina, ya que son claras expresiones del posicionamiento ideológico del medio en que se publican. Varios autores consultados sostienen que es el texto central de la publicación ya que

“...recoge el tema sobre el que el medio quiere pronunciarse de manera más clara, por considerarlo lo más importante. Es la voz del periódico"

Las entrevistas realizadas, el análisis de temas y palabras frecuentes en los editoriales y la exploración narrativa de estos nos permitieron delimitar etapas en la vida de JCS. En esta comunicación nos centraremos en las iniciales, a las que denominamos los años de formación (primera) y los años del exilio (segunda), esta última dividida entre 
la militancia política y la profundización de su formación y su trabajo profesional, durante su estadía en Francia. Las entrevistas en profundidad semiestructuradas iluminan la complejidad de una vida y, mediante la guía de preguntas, delimitan los campos de interés académico, la naturaleza de las líneas editoriales y su evolución a lo largo del tiempo. Instrumentamos un diálogo entre las entrevistas y el análisis de temas y palabras frecuentes con el objeto de vislumbrar el lugar que ocupó la revista en la vida de JCS y el lugar que ocupó JCS en la fundación y posterior edición de Vertex: él fue autor de los editoriales y encargado de seleccionar los temas sobre los cuales estos versaban. Expresa Laclau en el prefacio de un libro sobre biografías ${ }^{9}$ :

“¿Qué es, en primer término, lo que determina la centralidad del relato, de la narrativa? Algo requiere ser narrado en la medida en que su especificidad escapa a una determinación teórica directa, a un complejo institucional autorreferencial".

Creemos que este párrafo hace referencia a la gran dificultad que plantea capturar la complejidad de una vida; es por eso que la combinación de diferentes métodos de análisis nos aporta una mayor profundidad a la hora de compaginar los resultados del proceso de investigación.

Estamos atentos a la advertencia de Chul Han cuando plantea que vivimos una época posnarrativa, ya que-según él- lo que define nuestra vida no son las narraciones sino los recuentos ${ }^{10}$; nuestra propuesta considera esta advertencia jerarquizando la historia de la persona y la historia de la publicación puesta en tensión con los editoriales. Se realizó el registro de temas y palabras que aparecían con más frecuencia en los 150 editoriales de Vertex, que abarcan desde agosto de 1990 hasta abril de 2020. Con esta base se confeccionó una guía que fue depurada y analizada hasta llegar a obtener 35 preguntas. Las respuestas fueron procesadas y, en los casos que se consideró necesario, se definió una instancia de repreguntas para ampliar y profundizar los contenidos ${ }^{11}$.

La guía de pautas se elaboró sobre la base de las siguientes dimensiones: formación personal y profesional, hitos biográficos, relación personal con las revistas de psiquiatría existentes, la revista Vertex y los editoriales.

La técnica de recolección de la información utilizada fue la entrevista en profundidad ${ }^{12}$. Dada la relación personal existente de uno de nosotros (DM) con el entrevistado, las dos primeras entrevistas fueron realizadas por una de las integrantes del equipo (DZ) que, si bien conoce a JCS, no mantiene con él una relación laboral que pudiera ocasionar sesgos ${ }^{11}$. Se realizaron, luego de aplicar un consentimiento informado oral, en julio de 2020, a través de la plataforma Zoom $^{\circledR}$, y fueron desgrabadas y transcriptas.

La dinámica se estructuró sobre la base de una relación de confianza y empatía plenas, lo que permitió que el entrevistado se sintiera muy cómodo para hablar y pudiera ahondar en las temáticas abordadas en forma detallada. Luego del análisis inicial, se realizó una tercera entrevista, esta vez a cargo de LDM, para consultar por temas puntuales o aclaraciones de un tema específico.

\section{LOS AÑOS DE FORMACIÓN}

Es curioso cómo los años de formación se ven ampliamente reflejados en la manera como que la revista Vertex fue estructurada, y a su vez, esta estructura se manifiesta desde el primer editorial, en donde se define el programa desarrollado a lo largo de los diferentes números:

"Nacida del esfuerzo de un grupo de psiquiatras, esta revista es la realización de un deseo y la expresión de una necesidad colectivos: crear un espacio nuevo en el seno de la psiquiatría argentina. Abierta a las distintas orientaciones que atraviesan el campo psiquiátrico, pretende ser un lugar de confrontación, de memoria y de enseñanza. Hemos decidido dividirla en cuatro secciones; la primera, 'Revista de experiencias clínicas y neurociencias', comporta trabajos centrados sobre la práctica clínica y la incidencia de las neurociencias sobre ella. La segunda, 'Dossier', pretende abundar sobre un tema clínico preciso abordándolo desde diversas perspectivas. La tercera, 'El rescate y la memoria', apunta a llevar a nuestros lectores textos de los fundadores de la psiquiatría frecuentemente inhallables en nuestras bibliotecas. Ellos serán elegidos a la vez por su interés científico e histórico. También tendrán cabida en esta sección documentos y testimonios de la historia más reciente de nuestra especialidad en Argentina. La cuarta, 'Confrontaciones', de corte más periodístico se abre al debate, la actualidad y la información".

Clínica, historia, memoria, enseñanza, diversidad de perspectivas, debate, discusión, política son términos que se irán amplificando con el correr de los números, siempre enmarcados por "lo colectivo" y en tensión con las diferentes épocas y circunstancias.

Las entrevistas dejan claro que, desde el comienzo, quedan planteados los grandes temas que acompañarán a JCS a lo largo de su vida y que marcaron la historia de Vertex. A través del análisis de estas hacemos un punteo que incluye la lectura, la filosofía, la militancia política, la medicina, la salud pública y la investigación.

En la apertura de las entrevistas relata las dudas que se le plantearon entre seguir las carreras de Filosofía o de Medicina, lo que permite comenzar a pensar algunas de las líneas seguidas por la revista:

“...cuando tuve que hacer mi opción vocacional dudé entre la medicina y la filosofía, no sabía muy bien en esa época adolescente, había empezado muy chico a leer, asistemáticamente podríamos decir, mis padres eran muy lectores...mi padre era un tipo al que le gustaba mucho leer historia... yo entré a estudiar medicina porque me intrigaba todo lo biológico y pensé que iba 
a mantener una familia más como médico que como filósofo... además algo tuvieron que ver otras experiencias de enfermedades en miembros muy queridos en mi familia que, seguramente, despertaron en mí el impulso de querer curar a las personas y evitar que pasaran esas cosas".

Otro tema muy importante es la política:

"...mi padre era un hombre muy politizado, nacionalista y peronista... mi madre era hija del fundador del partido socialista de Paraná. Ella se inclinaba más por la literatura, especialmente la poesía y me hizo conocer a Neruda, Whitman, Lorca, Hernández, los poetas gauchescos y muchos otros. Mi viejo me hizo leer a Jauretche, a Scalabrini Ortiz, a José María Rosa, a los autores revisionistas, a Rodolfo Puiggrós, siendo yo muy chico. Además, como había una gran biblioteca en casa, durante el secundario leía ingenuamente a Dostoievsky, Nietzsche, Schopenhauer y muchos otros autores, en una mezcla con la poesía, que me atraía mucho, y los textos bíblicos y las encíclicas sociales porque, en esa época, me integré a la Juventud Estudiantil Católica en mi colegio que tenía una línea post-conciliar inscripta en el evangelio de la liberación. Poco después descubrí el marxismo y leí sus textos principales y, antes de recibirme de médico, me integré a la Juventud Peronista; entonces fue el momento en que comencé a leer a Perón, a Hernández Arregui, a Cooke y, en paralelo a Freud. Desde el secundario, como muchos de mi generación aprendimos, a los dieciséis, diecisiete años, cómo organizarse, cómo procesar políticamente ideas, cómo presentarlas, cómo escribirlas".

Una clave para pensar los editoriales: JCS, como se desprende de su relato, es un gran lector, no necesariamente o no solamente de medicina, quizás esta sea una de las explicaciones de por qué los editoriales tengan tantas claves narrativas a lo largo del tiempo; el hecho de que exista una "gran biblioteca" durante los años de formación permite pensar en los aspectos humanistas de la publicación (Cuadro 1). Medicina, política, religión y filosofía: de la mezcla de estos componentes surgirá su impronta en una revista científica en los comienzos de la década del 90, una de las décadas más complejas de la historia argentina; caracterizada por una de las más feroces crisis inflacionarias que sufrió el país, producto de la herencia del endeudamiento externo de la dictadura militar y del fracaso de las políticas implementadas por el gobierno de Alfonsín para superarlo ${ }^{13}$. Las discusiones familiares "con las pastas del domingo", las reuniones juveniles en los ámbitos militantes, fundamentalmente sobre temas relacionados con la política y la religión podrían ser pensadas como un lejano antecedente de las reuniones de los sábados del comité de redacción de Vertex a lo largo de treinta años, en las cuales las diferentes miradas teóricas de quienes participaban contribuyeron a la creación de un clima de debate continuo sobre la especialidad.

Podemos decir que los intereses de JCS determinaron que, a lo largo de la carrera de Medicina, las asignaturas estuvieran intercaladas con cursos sobre política. El primer contacto con lo psi fue durante el primer año de la Unidad Hospitalaria en el hospital Rawson en el que se introdujo la asignatura Psicología Médica; la lectura del texto de Jorge Insúa ${ }^{14}$, pero sobre todo su encuentro con el doctor Horacio Echegoyen, con su visión médica y psicoanalítica particularmente amplia y profunda, establecieron el marco para que los disímiles intereses comenzaran a amalgamarse:

"...después me di cuenta de que había encontrado un camino que podía volver a unir mis dos vocaciones, la filosofía y las humanidades con la medicina".

Es así como JCS va construyendo una visión de la medicina que se aleja del modelo biomédico hegemónico, y se acerca al modelo médico social caracterizado por “...una concepción social, epidemiológica y comunitaria de la salud con un enfoque antropológico que integra la biología y las relaciones sociales del paciente, dirigido hacia la prevención, la promoción de la salud y el logro de un estado de bienestar, así como al rescate de los procesos naturales y al involucramiento del paciente como sujeto activo en el acto diagnóstico, la orientación y la toma de decisiones"15. Este enfoque privilegia el contexto económico, político e ideológico de la sociedad.

\section{LOS AÑOS DEL EXILIO}

Como se señala en el cuadro 2, JCS tuvo que exiliarse en Francia durante la dictadura militar que se inicia en 1976. Aunque muchas personas exiliadas eligieron México y España por la afinidad idiomática, por vínculos familiares que le permitieron establecer contacto con diplomáticos

Cuadro 1. Principales pensadores que influyeron en la formación de JCS

\begin{tabular}{llc}
\hline Nombre & \multicolumn{1}{c}{ Temática } & Nacimiento/muerte \\
\hline Arturo Jauretche & Política-historia & $1901-1974$ \\
Raúl Scalabrini Ortiz & Filosofía-periodismo & $1898-1959$ \\
José María Rosa & Historia-política & $1906-1991$ \\
Rodolfo Puiggrós & Historia-política & $1906-1980$ \\
Horacio Etchegoyen & Medicina-psicoanálisis & $1919-2016$ \\
\hline
\end{tabular}


de ese país él eligió Francia, un centro de psiquiatría por excelencia. Se considera que, en esos años, un grupo de unos 3000 argentinos y argentinas llegaron a ese país y se ubicaron, en su gran mayoría, en París o áreas cercanas ${ }^{16}$. Algo menos de un tercio de ellos accedieron al asilo que otorgaba el OFPRA (Office Français des Refugiés et Apatrides) y que les daba un estatus de seguridad del que no se disponía en otros países ${ }^{17}$. Otros disponían de un pasaporte europeo que les permitía residir legalmente en el territorio francés sin necesidad de afrontar este tipo de trámites administrativos, o recurrieron a otras vías para residir legalmente, como por ejemplo la carta de residente para estudiantes. Además estaban quienes llegaron con visado de turista y que no siguieron las normas administrativas vigentes; $y$, por su propia condición de ilegales, resultan de difícil cuantificación ${ }^{18}$.

Una de las primeras actividades que emprendieron estos exiliados, tanto en Francia como en otros países, fue la organización de agrupaciones en defensa de los derechos humanos y la oposición a la dictadura, que, según detalla Franco,

“... funcionaban bajo el estatuto de asociaciones sin fines de lucro según lo contempla en Francia la Ley de 1901, y en algunos casos, además, según clivajes políticos y/u ocupacionales"17.

De manera simultánea con su formación psiquiátrica, JCS pasa a integrar la Comisión Argentina de Derechos Humanos en Francia y desarrolla una intensa labor en la denuncia del Terrorismo de Estado que imperaba en la Argentina ${ }^{18}$ : siempre lo académico y lo político fueron de la mano.

La elección de Francia como país de exilio tiene profundas implicaciones teóricas acerca de cómo a posteriori se fue diagramando la revista; Stagnaro rápidamente comienza a trabajar en la clínica de Charles Brisset, quien fue coautor, junto con Henry Ey y Paul Bernard, de uno de los manuales que por décadas se utilizó en la formación de los psiquiatras en la Argentina ${ }^{19}$.

En Francia rehace su especialización en psiquiatría, pero deja la práctica de la psiquiatría infantil, que era en lo que se había especializado en Buenos Aires, y se orienta a la clínica con pacientes adultos.

En este momento aparece un elemento que adquiere gran importancia y que se verá reflejado a lo largo del desarrollo de los editoriales de la futura revista: por un lado la clínica francesa con su gran componente antropológico, humanístico y filosófico. Tres revistas de psiquiatría francesas, L'Information Psychiatrique, Nervure y Synapsis (Fig. 2A, B y C) son reconocidas por JCS como una fuente de inspiración para editar Vertex 10 años más tarde (Fig 2D). La primera, creada en 1945, es la revista oficial del Syndicat des psychiatres des hôpitaux (SPH) de Francia (JCS es corresponsal en la Argentina de esta publicación hasta hoy), Nervure, Journal de Psychiatrie, fue creada en 1986 por François Caroli, a la sazón Jefe de Servicio en el Hospital Sainte Anne de París y Synapse Journal de psychiatrie et du système nerveux central, creada en 1984 por Markos Zafiropoulos.

Especialmente, las últimas dos publicaciones mencionadas se caracterizaron por una edición ágil, moderna en su concepción de diseño gráfico, e incorporaron ilustración y recursos de periodismo científico, especialmente entrevistas a personalidades de la psiquiatría, el psicoanálisis, la filosofía y las ciencias sociales. En Vertex se retomaron algunos de estos recursos combinados con otros que fueron surgiendo con el correr de los años, tanto en el entramado de la revista como en los editoriales. En estos últimos, una marca que imprime Stagnaro es el cruce de la disciplina con lo político y con la actualidad, en una similitud con el editorial periodístico. En este sentido, los condicionantes ideológicos que modulan la incorporación de ideas o la elaboración de un pensa-
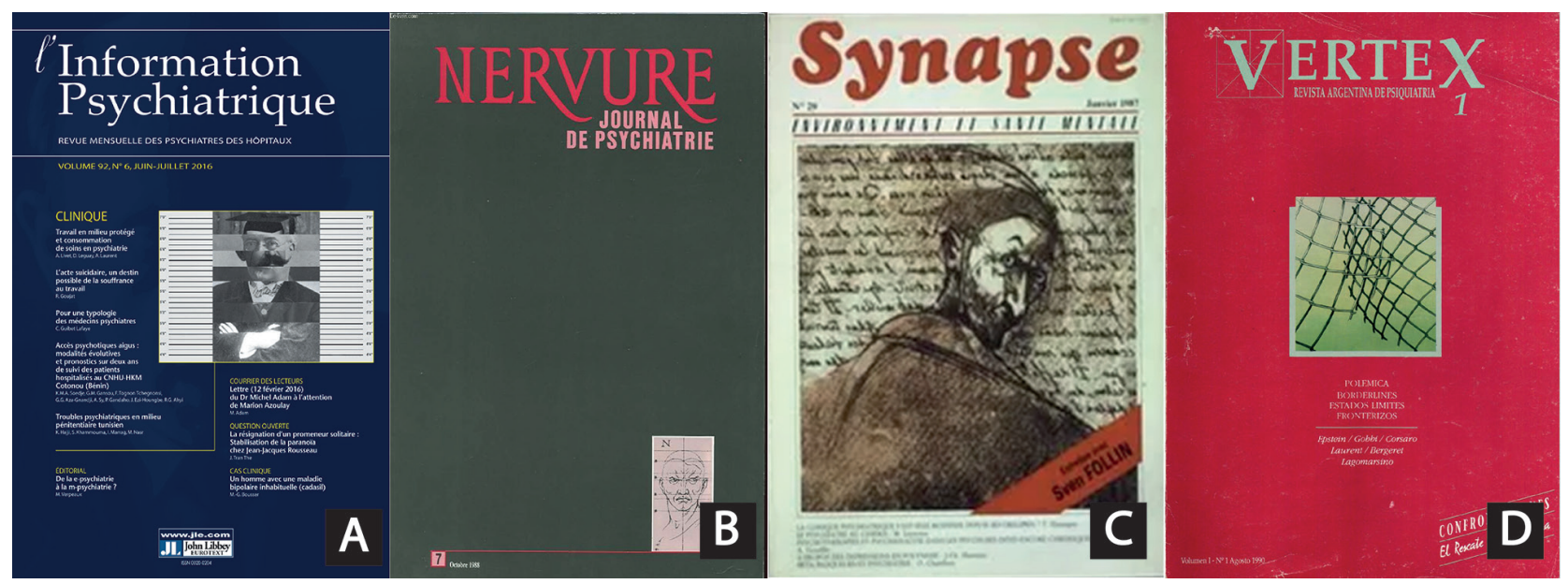

Figura 2. Las revistas de psiquiatría L'Information Psychiatrique (A), Nervure (B) y Synapse (C), que más influyeron en Stagnaro para, posteriormente, fundar Vertex (D). 
Cuadro 2. Breve biografía de Juan Carlos Stagnaro

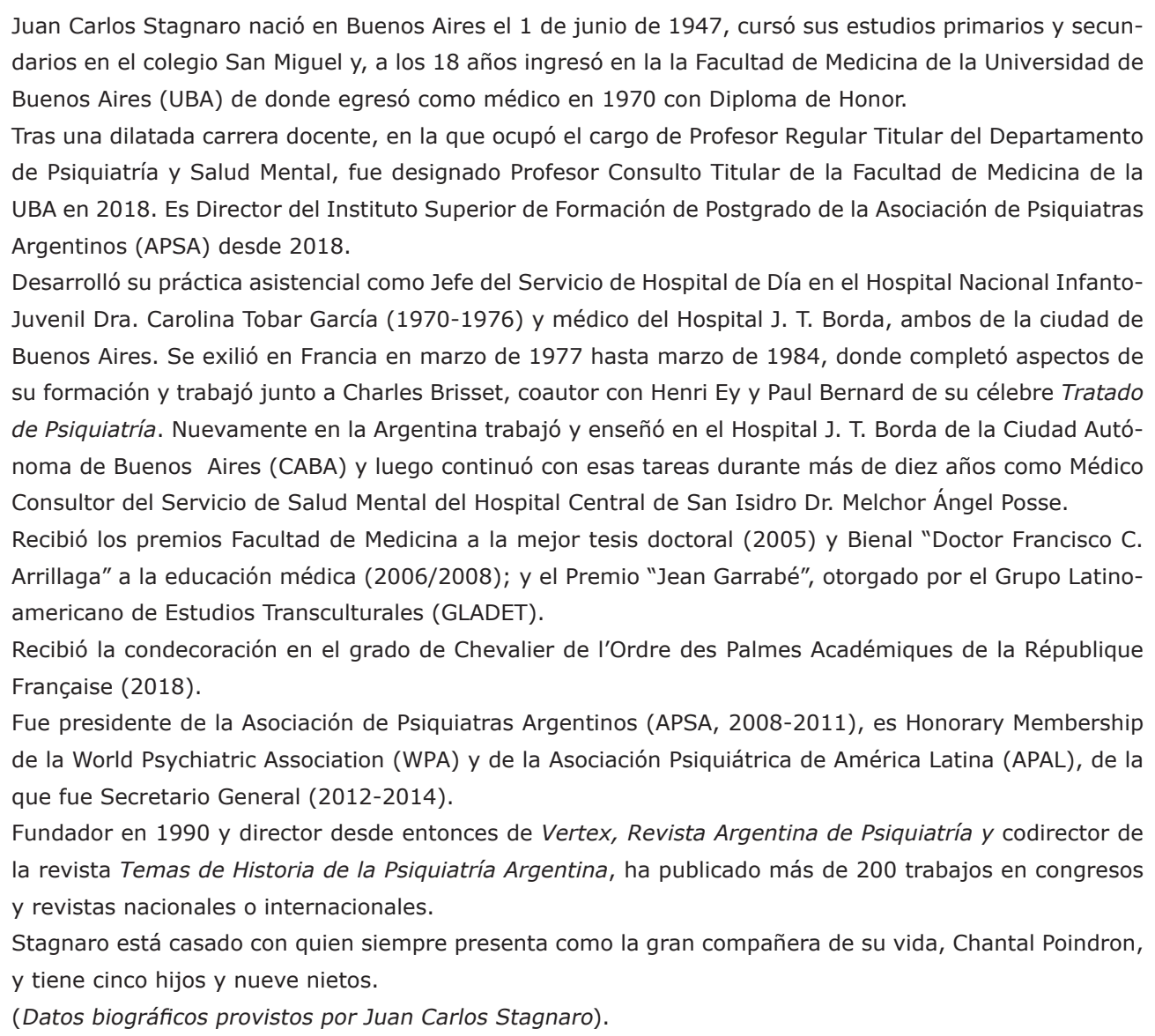

miento situado (para el caso ciencia nacional) a partir de una toma de posición del intelectual híbrido (pensar con la cabeza en el mundo y los pies en la Argentina) que se forma en una cultura de país periférico se trasladan e insertan en la práctica social. No como turista ni becario, si no como trabajador, en un país central, y vuelve con experiencia y pensamiento crítico a construir en el lugar originario: JCS es un exponente claro de este tipo de hombre.

\section{LOS AÑOS DE GESTACIÓN}

En el caso de JCS y, a diferencia de mucha otra gente que respondió al llamado de Bayer y a impulsos propios para retornar rápidamente al país ${ }^{20}$, él continuó su trabajo en Francia unos años más. Esto le permitió, por un lado, esquivar el riesgo de instalarse en lo que Yankelevich y Jensen dieron en llamar "territorio del exilio-desexilio", que está conformado por aquellas personas que nunca se terminaron de ir pero que jamás pudieron terminar de volver ${ }^{21}$.

Por otro lado, esos años fueron claves para madurar el proyecto de fundación de la revista, que generó una fuerte marca identitaria en JCS y que lo sigue acompañando treinta años después. En efecto, el análisis de palabras de los editoriales arroja que conceptos como Psiquiatría, Salud Mental, Ética, Historia y Política tienen una gran relevancia en la construcción de las líneas editoriales de la revista: $76 \%$ de los 150 editoriales contienen una o más de estas palabras (Cuadro 3), como los Editoriales 2, 78, 100 o 1241 ${ }^{1}$. Estas ideas acompañaron a JCS en la gestación de su proyecto científico, junto con otras experiencias, que

Cuadro 3. Palabras más frecuentes en los editoriales

\begin{tabular}{lll}
\hline & $\mathrm{n}$ & $\%$ \\
\hline Psiquiatría & 60 & 40 \\
Salud mental & 58 & 39 \\
Ética & 34 & 23 \\
Historia & 30 & 20 \\
Política & 24 & 16 \\
& & \\
\hline
\end{tabular}

El \% es superior a 100 puesto que algunas palabras se repiten en un mismo editorial. 
encaró a su retorno a la Argentina. Él mismo, en una de las entrevistas, señala:

“...cuando volví a Argentina me encontré con los viejos amigos que no se habían ido y que habían seguido ejerciendo y trabajando y me volví a encontrar con Etchegoyen. Me encontré con toda una historia previa, cosa que para muchos exiliados que se habían ido mucho más jóvenes o sin formación la reinserción fue mucho más complicada". JCS traza su trayectoria profesional convencido de que no existe conocimiento técnico despojado de significado subjetivo, personal y social. Así, marca su impronta en Vertex: todo acto médico es un acto político. Sus experiencias de vida traducidas en sus "verdades narrativas" son signo de su identidad profesional.
Al decir de Meccia, "los relatos del yo construyen imágenes públicas de ese yo"'22. En este sentido, en la construcción de los relatos de JCS se evidencia lo señalado por Arfuch" en tanto estos constituyen "un verdadero laboratorio de la identidad".

En ese laboratorio dialogan múltiples voces que reflejan lo vivido y le dan sentido, a la vez que contribuyen a conformar un interlocutor significativo con quien dialogar desde Vertex.

Este trabajo sobre los años tempranos de Stagnaro posibilita apreciar el caldo de cultivo en que, pocos años después, surgiría la revista y constituye un punto de anclaje para analizar, en el futuro, la génesis de Vertex y su particular visión de la psiquiatría.

\section{REFERENCIAS BIBLIOGRÁFICAS}

1. Vertex Revista Argentina de Psiquiatría. http://www.polemos.com.ar/vertex.php 2. PubMed. https://pubmed.ncbi.nlm.nih.gov/ 3. Franco M y Lvovich D. Historia Reciente: apuntes sobre un campo de investigación en expansión. Boletín Instituto Historia Argentina y Americana Dr. Emilio Ravignani. 2017; 47:190-201.

4. Levin S. La psiquiatría en la encrucijada. Buenos Aires: Eudeba; 2018.

5. Solnit R. Una guía sobre el arte de perderse. Buenos Aires: Fiordo; 2020.

6. Alcíbar Cuello M. Propuesta pragmáticodiscursiva para analizar artículos editoriales: modelo y estrategias. Estudios sobre el Mensaje Periodístico. 2015;21(1):225-41.

7. Fernández Barrero MÁ. El editorial. Un género periodístico abierto al debate. Sevilla: Comunicación Social Ediciones y Publicaciones; 2015.

8. Yanes Mesa R. El artículo, un género entre la opinión y la actualidad. Revista Latina de Comunicación Social. 2004;7(58):1-15.
9. Arfuch L. El espacio biográfico. Dilemas de la subjetividad contemporánea. 2. ${ }^{\text {a reimp. Bue- }}$ nos Aires: Fondo de Cultura Económica; 2007.

10. Byung-Chul H. La sociedad paliativa. Barcelona: Herder; 2021.

11. Kvale S. La entrevista en Investigación Cualitativa. Madrid: Morata; 2011.

12. Hernández Sampieri R, Fernández Collado C, Pilar Baptista L M. Metodología de la investigación. 5.a ed. México: McGrawHill; 2014.

13. Romero LA. La violencia en la historia argentina reciente: un estado de la cuestión. En: Pérotin-Dumon A (dir.). Historizar el pasado vivo en América Latina, 2007. p. 3. http://etica.uahurtado.cl/ historizarelpasadovivo/es_contenido.php 14. Insúa J A. Psicología Médica. Buenos Aires: Columba; 1967.

15. Artiles Visbal L. El proyecto magisterio y la categoría género en la formación de recursos humanos en salud. Instituto Superior de Ciencias Médicas de La Habana;
2005. http://scielo.sld.cu/pdf/ems/v19n2/ ems01205.pdf

16. Franco M. El exilio. Argentinos en Francia durante la dictadura. Buenos Aires: Siglo XXI; 2008.

17. Franco M. Testimoniar e informar: exiliados argentinos en París (1976-1983). Les cahiers ALHIM. 2004; 8. https://doi. org/10.4000/alhim.414

18. Franco M, Bernaldo P. Cuando el sujeto deviene objeto: la construcción del exilio argentino en Francia. https://hal.archivesouvertes.fr/hal-01935085

19. Ey H, Bernard P, Brisset C. Tratado de Psiquiatría. 2.a ed. Buenos Aires: Masson; 1995.

20. Bayer O. Una propuesta para el regreso. Controversia. 1980;7(2):7.

21. Yanquelevich $\mathrm{P}$, Jensen S. Exilios. Destinos y experiencias bajo la dictadura militar. Buenos Aires: El Zorzal; 2007.

22. Meccia E. Biografías y sociedad: métodos y perspectivas. Santa Fe: Universidad Nacional del Litoral; 2020. p. 54. 